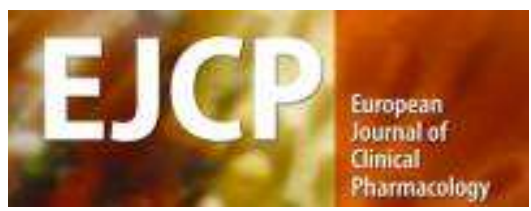

\title{
OFF-LABEL ANTIBIOTIC USE IN CHILDREN IN THREE EUROPEAN COUNTRIES
}

\begin{tabular}{|r|l|}
\hline Journal: & European Journal of Clinical Pharmacology \\
\hline Manuscript ID: & EJCP-2009-0388.R1 \\
\hline Type of submission: & Original \\
\hline Duthor: & 18 -Apr-2010 \\
\hline Complete List of Authors: & $\begin{array}{l}\text { Porta, Alessandro; Università degli Studi di Milano, Fondazione } \\
\text { IRCCS Ospedale Maggiore Policlinico, Mangiagalli e Regina Elena, } \\
\text { Department of Maternal and Pediatric Sciences } \\
\text { Esposito, Susanna; Università degli Studi di Milano, Fondazione } \\
\text { IRCCS Ospedale Maggiore Policlinico, Mangiagalli e Regina Elena, } \\
\text { Department of Maternal and Pediatric Sciences } \\
\text { Menson, Esse; Evelina Children's Hospital, Pediatrics } \\
\text { Spyridis, Nikos; P. and A. Kyriakou Children's Hospital, Department } \\
\text { of Pediatrics, University of Athens } \\
\text { Tsolia, Maria; P. and A. Kyriakou Children's Hospital, Department of } \\
\text { Pediatrics, University of Athens } \\
\text { Sharland, Mike; St George's Hospital, Pediatric Infectious Diseases } \\
\text { Unit } \\
\text { Principi, Nicola; Università degli Studi di Milano, Fondazione IRCCS } \\
\text { Ospedale Maggiore Policlinico, Mangiagalli e Regina Elena, } \\
\text { Department of Maternal and Pediatric Sciences }\end{array}$ \\
\hline \hline
\end{tabular}

\section{ScholarONE Manuscript Central}




\section{OFF-LABEL ANTIBIOTIC USE IN CHILDREN IN THREE EUROPEAN COUNTRIES}

Alessandro Porta ${ }^{a}$, Susanna Esposito ${ }^{a}$, Esse Menson ${ }^{b}$, Nikos Spyridis $^{c}$, Maria Tsolia $^{c}$, Mike Sharland ${ }^{d}$, Nicola Principi ${ }^{\mathrm{a}}$

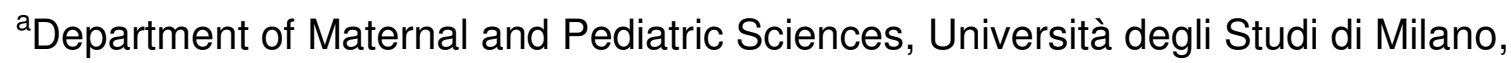
Fondazione IRCCS Ospedale Maggiore Policlinico, Mangiagalli e Regina Elena, Milan, Italy; ${ }^{b}$ Evelina Children's Hospital, London, United Kingdom; ${ }^{c} \mathrm{P}$. and A. Kyriakou Children's

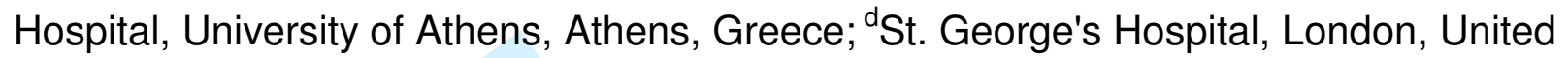
Kingdom.

Shortened title: Off-label antibiotics in children.

Key words: Antibiotics; antibiotic use; antimicrobials; antimicrobial prescribing; off-label drugs; children.

Abstract: 250 words.

Text: 3,161 words.

Correspondence and requests for reprints should be addressed to:

Nicola Principi,

Department of Maternal and Pediatric Sciences,

Università degli Studi di Milano,

Fondazione IRCCS "Ospedale Maggiore Policlinico, Mangiagalli e Regina Elena”, 


\author{
Via Commenda 9, \\ 20122 Milano, \\ Italy \\ Phone: +39-02-55032498; Fax: +39-02-50320206 \\ E-mail: Nicola.principi@unimi.it
}

\title{
ABSTRACT
}

Objective. Antibiotics are the drugs most frequently prescribed for children, and most of them lack patent protection. The aim of the present study was to evaluate off-label antibiotic use in three European countries.

Methods. The data concerning all patients admitted to the neonatal intensive care units (NICUs) and pediatric wards of the centers were collected by the same investigator over a two-week survey period between February and May 2009. Data included age, date of birth, weight, relevant medical history and diagnosis, together with details of all of the antibiotics prescribed (compound, route of administration, dose and indication for use). Results. The study involved 616 children (110 admitted to NICUs: 62 in the UK, 38 in Italy, and 10 in Greece; and 506 admitted to general pediatric wards: 265 in the UK, 94 in Italy and 147 in Greece) and a total of 1244 antibiotic prescriptions were issued (290 in NICUs and 954 in pediatric wards). The results show that off-label antibiotic use is very common in European pediatrics, with only slight but sometimes significant differences between countries. However, this use relates almost exclusively to doses and indications, and rarely to age. The only antibiotics used off-label for age in pediatric clinical practice were 
meropenem for neonates and quinolones or linezolid for older children, which represent priorities for future studies.

Conclusion. European-wide educational programmes are urgently needed to meet the objectives of improving paediatricians' working knowledge of the recommendations surrounding licensed antibiotics-use in children, and of reducing uncontrolled patterns of prescribing. 


\section{INTRODUCTION}

A number of hospital- and office-based studies have shown that many of the drugs prescribed to children are used outside their registered doses, age groups, indications and routes of administration [1-12]. This off-label use is related to the practical and ethical difficulties in carrying out clinical trials involving very young subjects. The extensive research required by current standards of drug evaluation in order to register a specific product for paediatric use is often not supported by the profit-driven drug industry because children represent only a small part of the drug market [13]. Furthermore, the limited pediatric drug research that is carried out is often based on small-scale studies that lack the statistical power necessary to draw any firm conclusions concerning the real efficacy of the drugs or their long-term toxic effects [14]. Ethical conflicts are heightened where the toxicity of medicines may be different in children and adults, compounded by issues around informed consent and assent [15].

Off-label drug use can cause significant damage in the developing fetus or child, one of the best examples being the grey baby syndrome due to chlorampenicol $[16,17]$; but it also gives rise to many minor but not marginal adverse events requiring hospitalisation or additional therapies [18-22]. A number of health authorities have recognised the need to conduct specific studies in children in order to reduce the problem of off-label use. The American Food and Drug Administration (FDA) has prepared the Best Pharmaceutical for Children Act and the Pediatric Research Equity Act, both of which are intended to incentivise drug research in children [23,24]: the first allows companies to qualify for an additional six months' exclusive marketing of a specific molecule provided that they carry out specific paediatric trials [23], and the second, which became law in 2003, states that the FDA can require pediatric studies of a drug for which a new drug application is 
submitted if it finds that the product is likely to be used in a substantial number of pediatric patients or would provide a significant benefit over existing treatments [24]. The European Medicines Agency (EMEA) has laid down specific rules for marketing authorisations of new medicinal products and for pediatric-use marketing authorisations of off-patent products [25]. It has also agreed a strategy for establishing the European network of pediatric research and providing information concerning pediatric clinical trials. Moreover, in order to encourage studies of drugs that lack patent protection because they have been marketed for many years, it has decided to prepare a list of drugs for which studies in children are urgently needed and can be financed by the European Union [26].

The drugs most frequently prescribed for children are antibiotics $[27,28]$, most of which lack patent protection. The aim of the present study was to evaluate off-label antibiotic use in three European countries.

\section{METHODS}

Antibiotic prescriptions were evaluated for all inpatients in the neonatal intensive care units (NICUs) and the pediatric medical and surgical wards of two hospitals in UK (St George's Hospital and Evelina Children's Hospital in London), one in Italy (Department of Maternal and Pediatric Sciences of the University of Milan), and one in Greece (Aglaia Kyriakou Children's Hospital, University of Athens). All data on the four sites were collected by the same investigator (AP) during a two-week survey of each hospital between February and May 2009. Data included age, date of birth, weight, relevant medical history and diagnosis, together with details of all of the antibiotics prescribed (compound, route of administration, dose and indication for use). The protocol was approved by the Institutional Review Board 
of all centres, and written informed consent was obtained from a parent or legal guardian, with children aged more than eight years being asked to give their assent.

Off-label antibiotic use was determined on the basis of the information concerning product registration given in the British National Formulary 2009, the Italian Informatore Farmaceutico, and the Greek National Formulary 2006, as well as package insert information and what could be derived from the medical information departments of the pharmaceutical companies concerned. Off-label use was defined as the administration of an antibiotic in situations not covered by the product licence or the summary of product characteristics, or at a different dose or frequency, or to different age groups, or by means of an alternative route. The age groups considered were those defined by EMEA: neonates (0-27 days), infants (28 days to 23 months), children (2-11 years) and adolescents (12-17 years). The prescriptions were then divided into three groups depending on whether the off-label use was related to the patient's age, the drug dose, or the indication. A difference of $10 \%$ between the physician's prescription and the reference dose was allowed before considering the administration off-label.

Results were compared using SAS software, version 9.1 (SAS Institute, Cary, North Carolina). In Tables, only antibiotics prescribed at unregistered dose or for an off-label indication in more than $5 \%$ of the prescriptions in at least one of the centers are shown. Categorical variables are reported as numbers and percentages, and analysed by means of contingency tables and the chi-squared or Fisher's test. Continuous variables are given as mean values \pm standard deviation (SD), and analysed using a t test or Wilcoxon's test (for non-normally distributed data). P-values of 0.05 or less were considered to be statistically significant. 


\section{RESULTS}

\section{Study population}

The study involved a total of 616 children (110 admitted to NICUs: 62 in the UK, 38 in Italy, and 10 in Greece; and 506 admitted to pediatric wards: 265 in the UK, 94 in Italy and 147 in Greece); a total of 1244 antibiotic prescriptions were issued for these patients (290 in NICUs and 954 in pediatric wards). Table 1 shows the demographic characteristics of the study patients. For NICU patients, there were no significant between-country differences in gender or age, or in the presence of underlying chronic conditions, number of antibiotic prescriptions, number of antibiotics used, or clinical indications for the antibiotic prescriptions. On pediatric wards, significantly more children in the neonatal age group were admitted in the UK than in Italy or Greece, and significantly fewer children aged 2-11 years were admitted in the UK than in Greece, while both UK and Italy hospitalised significantly more pediatric patients with underlying chronic diseases than Greece. However, there were no significant between country differences in gender, number of antibiotic prescriptions, number of antibiotics used, or clinical indications for the antibiotic prescriptions on paediatric wards.

\section{Antibiotic prescribing in neonatal units}

There were 12 episodes out of 290 prescriptions in which antibiotics were used outside the registered age range (4.1\%). Although there were small number of neonates in the Greek NICU during the study period, there were significantly fewer "outside age range" 
prescriptions in the UK $(4 / 172,4.3 \%)$ and Italy $(2 / 91,2.2 \%)$ than in Greece $(6 / 27,22.2 \%$; $\mathrm{p}<0.05$ vs UK and Italy). The most frequent of such prescriptions in all centres was for meropenem (10/12 episodes, $83.3 \%)$, which was prescribed because of proven or suspected sepsis in all cases. The Greek NICU also used imipenem (one case for lower respiratory tract infection) and ciprofloxacin (one case for urinary tract infection) outside age range. Moreover, the median gestational and chronological ages of the neonates in whom antibiotics were used outside the registered age range were significantly lower in Italy (median gestational age at birth 26 weeks and median age at prescription 24 days) than in the UK (median gestational age 31.7 weeks, $p<0.05$ vs Italy; median age 39.5 days, $p<0.05$ vs Italy) or Greece (median gestational age 33.7 weeks, $p<0.05$ vs Italy; median age 64 days, $p<0.05$ vs Italy). In the UK and Italian NICUs, the off-label use of antibiotics was related to patients with an underlying chronic disease in all cases, whereas in Greece this was true of only half of the cases.

Table 2 shows the antibiotics used at an unregistered dose in more than $5 \%$ of the prescriptions in at least one of the centers in patients admitted to NICUs. The number of such prescriptions was high in all of three countries, but significantly higher in Italy than in the UK. In all of the NICUs, the antibiotics most frequently prescribed at doses other than the recommended dose were aminoglycosides (particularly amikacin and gentamicin). Offlabel doses of gentamicin and also amoxicillin-clavulanate were prescribed significantly more often in the Italian NICU than in the UK units. In most cases, the differences regarded the administration of a lower than advised total daily dose or different fractioning. Higher than recommended doses were significantly more common in the Greek than in the UK NICUs. The most common clinical indication related to the use of off-label doses was 
proven or suspected sepsis in all three countries, although significantly more off-label doses for medical prophylaxis were prescribed in Italy and Greece than in the UK.

Table 3 shows the antibiotics used for an off-label indication in more than $5 \%$ of the prescriptions in at least one of the centers in the patients admitted to the NICUs. The prevalence of this use was similar in the UK and Greece, but higher in Italy. There were between-country differences in both the molecules and the individual indications. The antibiotics most frequently prescribed for an off-label indication were flucloxacillin in the UK, and ampicillin and gentamicin in Italy and Greece. The most common indications were suspected or proven sepsis in the UK, and medical prophylaxis in Italy and Greece. More Italian neonates with underlying chronic disease had off-label indications for the antibiotics received than UK or Greek neonates in NICUs.

\section{Antibiotic prescribing on paediatric wards}

Very few children in all centres received an antibiotic that was not licensed for pediatric use: there were 16 out of $954(1.7 \%)$ prescriptions in which antibiotics were used outside the registered age range. The antibiotics most frequently used outside the registered age range were quinolones $(11 / 16,68.8 \%)$ and linezolid $(5 / 16,31.2 \%)$, administered to children with a severe infection and an underlying chronic disease (mainly cystic fibrosis or leukemia). The median age of the patients receiving "outside age range" antibiotics was significantly higher in wards in the UK (median age at prescription 8.19 years) than in Italy (median age at prescription 4.25 years; $\mathrm{p}<0.05$ vs UK) or Greece (median age at prescription 0.41 years). 
Table 4 shows the antibiotics used at an unregistered dose in more than $5 \%$ of the prescriptions in at least one of the centers in patients admitted to pediatric wards. The proportion of prescriptions was quite similar in all of the centres, and the number of antibiotics involved was equally high across countries. In contrast, there were significant between-country differences in antibiotic choice, the most commonly prescribed being amoxicillin-clavulanate in Italy, cefuroxime in Greece, and gentamicin in the UK. The offlabel doses were mainly higher than advised in Italy and Greece, and lower than recommended in the UK. The main indications for off-label dosage were sepsis, lower respiratory tract infection and surgical prophylaxis in all three countries, with no difference in prevalence. Doses other than those recommended were used for children aged 28 days-23 months significantly more often in Italy than in the UK or Greece, with the median age of children receiving off-label doses being significantly lower in Italy than in the other two countries. Off-label doses were prescribed for children with underlying chronic disease significantly more often in the UK and Italy than in Greece.

Table 5 shows the antibiotics used for off-label indications in more than $5 \%$ of the prescriptions in at least one of the centers. The frequency of this use was significantly higher in the UK and Italy than in Greece. Amoxicillin-clavulanate was prescribed significantly more often in Italy than in Greece, and ampicillin-sulbactam significantly more often in Italy than in UK and Greece. The prevalence of use for off-label surgical treatment was significantly higher in the UK and Italy than in Greece. There were no significant between-country differences in the age distribution of the patients or the presence of an underlying chronic disease. 


\section{DISCUSSION}

Over the last few years, several studies carried out in different settings have clearly demonstrated that the off-label use of drugs is frequent in pediatrics, especially in neonates [1-12]. However, most of them have considered all drugs prescribed to children and provided little details of prescription practice. To the best of our knowledge, this is the first study evaluating off-label antibiotic use in pediatrics that takes into account all of the variables involved in a drug prescription: the age of the patient, the total daily drug dose and its fractioning, and the indication for treatment.

Our findings suggest that pediatric off-label antibiotic use is very common in Europe with only marginal but sometimes significant between-country differences. However, this offlabel use almost exclusively relates to doses and indications rather than age as the only antibiotics not registered for specific age groups that neonatologists and pediatricians sometimes deem imperative in very serious clinical situations were meropenem for neonates and quinolones or linezolid for older children.

Sepsis in an NICU is a life-threatening disease that requires prompt and effective antibiotic treatment [29]. Published recommendations suggest that the empirical therapy for newborns should be based on a combination of ampicillin and an aminoglycoside, although the latter can cause severe adverse events and has to be administered cautiously in the first months of life [29]. However, most of the pathogens that cause neonatal bacterial sepsis have become highly resistant to the first-choice combination, especially in the case of a late-onset and probable nosocomial origin [30]. This means that alternative antibiotic therapies are needed, particularly for neonates who remain in NICUs for several days, and justifies the use of meropenem in some cases. Meropenem has a 
broad antibacterial spectrum, a very good safety profile, and good pharmacokinetic and pharmacodynamic characteristics [31]. However, although it has been widely successfully used to treat severe infections, including bacterial sepsis and meningitis in children and infants aged $\geq 3$ months [32], it has not yet been registered for neonates and infants aged $<3$ months. Our data show that comprehensive clinical research into its use for severe infections in this age group is a clinical priority for neonatologists.

Quinolones and linezolid are not licensed for use during the first 18 years of life but studies of quinolones have clearly demonstrated that ciprofloxacin and levofloxacin (the molecules used in the centres involved in this study) can be administered to pediatric patients with good results and without any significant adverse events [33,34]. Nevertheless, the use of quinolones should be limited to diseases caused by pathogens resistant to all of the other licensed drugs because they may rapidly select antimicrobial resistance in the case their widespread and uncontrolled administration. The situation of linezolid is similar as it is a relatively new drug for which pediatric experience is limited to complicated infections in patients with underlying chronic disease [35-37]. We found that quinolones and linezolid were mainly used in children with cystic fibrosis or oncohematological diseases in which complicated infections due to bacterial resistance to commonly used antibiotics is very frequent. 
The high prevalence of antibiotic prescriptions for off-label indications or at unregistered doses in our NICUs and pediatric wards is in line with previously published data concerning the pediatric use of antibiotics [1-12]. It may be that pediatricians have a poor understanding of the properties and characteristics of antibiotics nor how they should be prescribed to treat bacterial diseases at different pediatric ages, but our findings raise some interesting afterthoughts.

First of all, certain antibiotics, especially aminoglycosides, were prescribed at below than recommended doses, mainly in the UK and Italian NICUs, which may reflect neonatologists' fear of known adverse effects [2] and a preferance to reduce the risk by limiting dosage rather than respecting published recommendations. The higher than recommended dosage of aminoglycosides observed for the NICU in Greece is difficult to explain, but it highlights the need for a comprehensive review of the dosing of potentially toxic antibiotics in such setting.

Secondly, the main off-label indications for which antibiotics were used in NICUs were proven or suspected sepsis in the UK, and medical prophylaxis in Italy and Greece. The rational approach to antibiotics in neonates involves using narrow-spectrum drugs whenever possible, treating infection and not colonisation, and limiting the duration of therapy [30], which makes it difficult to explain their use for off-label indications. It is possible that many of the antibiotics approved for use in neonates have been licensed for so long that the emergence of bacterial resistance is being observed or suspected, underpinning the tendency to move to off-license alternatives.

Thirdly, for the pediatric inpatient populations, the number of prescriptions made at unregistered doses could be due to clinicians translating the findings of well-conducted 
post-marketing studies into their clinical practice. Aminoglycosides serve as a good example of this: having been licensed with the recommendation to divide the total daily dose into two or three administrations depending on the patients' age and renal function, subsequent clinical trials have shown equivalent or superior clinical outcome from once daily dosing of the total daily dose, with a reduced lower risk of toxicity $[38,39]$. Similarly, amoxicillin, licensed in children at a recommended dose of $40-50 \mathrm{mg} / \mathrm{kg} / \mathrm{day}$, proved to be effective against Streptococcus pneumoniae strains with relative resistance to penicillin when used at higher dose $(80-90 \mathrm{mg} / \mathrm{kg} / \mathrm{day})$ without concomitant increase in the incidence of adverse events [40,41].

Evidence of the clinical effectiveness of other antimicrobials when used for off-label indications may also be influencing practice: for example, the use of macrolides for bronchitis or acute infectious wheezing was not considered appropriate until that the role of atypical bacteria was demonstrated in these diseases [42-44]. It may be, therefore that some of the off-label prescribing described in this study constituted active rational decision-making by clinicians based on the emerging evidence. However, how much offlabel prescribing is merely 'personal practice' error or experimentation without an appropriate clinical trial setting cannot be evaluated from this study.

In conclusion, although only four centres have been evaluated in our study and this limits the speculation on the possible causes of differences between countries as well as it does not really represent the entire European Union, our data confirm that the off-label use of antibiotics in newborns, infants and children is widespread and that the bulk of this cannot be justified on the grounds of optimizing clinical care. As suggested by the FDA and EMEA [23-26], studies of the antibiotics that are not licensed for specific pediatric age groups are urgently needed in order to evaluate how they should be administered in order to optimize 
clinical results while minimising the risk of adverse events. In the case of already licensed antibiotics, the studies performed after their licensing should be carefully reviewed and the recommendations modified when new knowledge acquired. Finally, national and European-wide educational programmes should meet the dual objectives of improving paediatricians' working knowledge of the recommendations surrounding licensed antibiotics-use in children, and of reducing uncontrolled patterns of prescribing that may increase the risk of antimicrobial resistance.

\section{ACKNOWLEDGEMENTS}

We would like to thank all of our colleagues who permitted data collection: Fabio Mosca, Lorenza Pugni, Maria Cristina Pietrogrande, Rosa Maria Dellepiane, Edoardo Calderini, Maurizio Torricelli at the Department of Maternal and Pediatric Sciences, Università degli Studi di Milano, Fondazione IRCCS Ospedale Maggiore Policlinico, Mangiagalli e Regina Elena, Milan, Italy; Dimitris Kafetzis, George Kourakis, George Petousis, Alexandros Passalidis at P. and A. Kyriakou Children's Hospital, University of Athens, Athens, Greece.

The authors have no conflict of interest to declare. This study was supported in part by a grant from the Pediatric Unit 1, Fondazione IRCCS Ospedale Maggiore Policlinico, Mangiagalli e Regina Elena, Milan, Italy. 


\section{REFERENCES}

1. Conroy S, Mclntre J, Choonora I (1999) Unlicensed and off label drug use in neonates. Arch Dis Child Fetal Neonatal Ed 80:F142-F144.

2. Conroy S, Choonara I, Impicciatore I et al. (2000) Survey of unlicensed and off label drug use in paediatric wards in European countries. European network for Drug Investigation in Children. BMJ 320:79-82.

3. Turner S, Longworth A, Nunn AJ, Choonara I (1998) Unlicensed and off label drug use in paediatric wards: prospective study. BMJ 316:343-345.

4. 't Jong GW, Vulto AG, de Hoog M, Schimmel KJ, Tibboel D, van den Anker JN (2001) A survey of the use of off-label and unlicensed drugs in Dutch children's hospital. Pediatrics 108:1089-1093.

5. Schirm E, Tobi H, De Jong-Van den Berg LTW (2002) Unlicensed and off label drug use by children in the community: cross sectional study. Br Med J 324:13121313.

6. Bucheler R, Schwab M, Morike K ey al. (2002) Off-label prescribing to children in primary care in Germany: retrospective cohort study. Br Med J 324:1311-1312.

7. Pandolfini C, Campi R, Clavenna A, Cazzato T, Bonati M (2005) Italian paediatricians and off-label prescriptions: loyal to regulatory or guideline standards? Acta Paediatr 94:753-757.

8. Sammons H, Conroy S (2008) How do we ensure safe prescribing for children? Arch Dis Child 93:98-99.

9. Conroy S, Carroll WD (2009) Prescribing in pediatrics. Arch Dis Child Educ Pract Ed 94:55-59. 
10. Tafuri G, Trotta F, Leufkens HGM, Martini N, Sagliocca L, Traversa G (2009) Offlabel use of medicines in children: can available evidence avoid useless pediatric trials? Eur J Clin Pharmacol 65:209-216.

11. de Jong J, van den Berg PB, Visser ST, de Vries TW, de Jong-van den Berg LTW (2009) Antibiotic usage, dosage and course length in children between 0 and 4 years. Acta Paediatr 98:1142-1148.

12.Lenk C, Koch P, Zappel H, Wiesemann C (2009) Off-label, off-limits? Parental awareness and attitudes towards off-label use in paediatrics. Eur J Pediatr 168:1473-1478.

13. Conroy S, Mclntyre J, Choonara I, Stephenson T (2000) Drug trials in children: problems and the way forward. Br J Clin Pharmacol 49:93-97.

14.Pandolfini C, Bonati M, Sammons H (2009) Registration of trials in children. Update of current international initiatives. Arch Dis Child 94:717-719.

15. Altavilla A, Giaquinto C, Ceci A (2008) European survey on ethical and legal frame work of clinical trials in paediatrics: results and perspectives. J Int Bioethique 19:1748.

16. Holt D, Harvey D, Hurley R (1993) Chlorampenicol toxicity. Adverse Drug React Toxicol Rev 12:83-95.

17. Mclntyre J, Choonara I (2004) Drug toxicity in the neonate. Biol Neonate 86:218221.

18. Horen B, Montastruc JL, Lapeyre-Mestre M (2002) Adverse drug reactions and offlabel drug use in paediatric outpatients. Br J Clin Pharmacol 54:665-670.

19. Clarkson A, Choonara I (2002) Surveillance for fatal suspected adverse drug reactions in the UK. Arch Dis Child 87:462-466. 
20.Choonara I, Conroy S (2002) Unlicensed and off-label drug use in children: implications for safety. Drug Saf 25:1-5.

21. Turner S, Nunn AJ, Fielding K, Choonara I (1999) Adverse drug reactions to unlicensed and off-label drugs on paediatric wards: a prospective study. Acta Paediatr 88:965-968.

22.Johann-Liang R, Wyeth J, Chen M, Cope JU (2009) Pediatric drug surveillance and the Food and Drug Administration's adverse event reporting system: an overview of reports, 2003-2007. Pharmacoepidemiol Drug Saf 18:24-27.

23.Best Pharmaceuticals for Children Act. Pub. L. 107-109, 107 ${ }^{\text {th }}$ Cong, 2002.

24.Pediatric Research Equity Act. Pub. L. No. 108155 (S.650), 2003.

25.Neubert A, Wong IC, Bonifazi A et al. (2008) Defining off-label and unlicensed use of medicines for children: results of a Delphi survey. Pharmacol Res 58:316-322.

26. Ceci A, Felisi M, Baiardi P et al. (2006) Medicines for children licensed by the European Medicines Agency (EMEA): the balance after 10 years. Eur J Clin Pharmacol 62:947-952.

27. Marchetti F, Bua J, Ventura A, Notarangelo LD, Di Maio S, Migliore G, Bonati M (2007) The awareness among paediatricians of off-label prescribing in children: a survey of Italian hospitals. Eur J Clin Pharmacol 63:81-85.

28. Clavenna A, Sequi M, Bortolotti A, Merlino L, Fortino I, Bonati M (2009) Determinants of the drug utilization profile in the paediatric population in Italy's Lombardy Region. Br J Clin Pharmacol 67:565-571.

29.Burke C (2009) Perinatal sepsis. J Perinat Neonatal Nurs 23:42-51.

30. Fernando AM, Heath PT, Menson EN (2008) Antimicrobial policies in the neonatal units of the United Kingdom and Republic of Ireland. J Antimicrob Chemother 61:743-745. 
31. Arrieta A (1997) Use of meropenem in the treatment of serious infections in children: review of the current literature. Clin Infect Dis 24 Suppl. 2:S207-S212.

32. Principi N, Marchisio P (1998) Meropenem compared with ceftazidime in the empiric treatment of acute severe infections in hospitalized children. J Chemother 10:108-113.

33. Mandell LA, Peterson LR, Wise R et al. (2002) The battle against emerging antibiotic resistance: should fluoroquinolones be used to treat children? Clin Infect Dis 35:721-727.

34. Schaad UB (2005) Fluoroquinolone antibiotics in infants and children. Infect Dis Clin North Am 19:617-628.

35. Velissarious IM (2006) Use of linezolid in children: an overiew of recent advances. Expert Rev Anti Infect Ther 4:947-952.

36. Kosaka T, Kokufu T, Shime N, Sugioka N, Kato R, Hamaoka K, Fujita N (2009) Pharmacokinetics and tolerance of linezolid for meticillin-resistant Staphylococcus aureus mediastinitis in paediatric patients. Int J Antimicrob Agents 33:368-370.

37.Santos RP, Prestidge CB, Brown ME et al. (2009) Pharmacokinetics and pharmacodynamics of linezolid in children with cystic fibrosis. Pediatr Pulmonol $44: 148-154$.

38. Rao SC, Ahmed M, Hagan R (2006) One dose per day compared to multiple doses per day of gentamicin for treatment of suspected or proven sepsis in neonates. Cochrane Database Syst Rev 1:CD005091.

39. Hagen I, Øymar K (2009) Pharmacological differences between once daily and twice daily gentamicin dosage in newborns with suspected sepsis. Pharm World Sci 31:18-23. 
40.Dowell SF, Butler JC, Giebink GS et al. (1999) Acute otitis media: management and surveillance in an era of pneumococcal resistance - a report from the Drugresistant Streptococcus pneumoniae Therapeutic Working group. Pediatr Infect Dis J 18:1-9.

41.Piglansky L, Leibovitz E, Raiz S, Greenberg D, Press J, Leiberman A, Dagan R (2003) Bacteriologic and clinical efficacy of high dose amoxicillin for therapy of acute otitis media in children. Pediatr Infect Dis J 22:405-413.

42.Principi N, Esposito S, Blasi F, Allegra L, the Mowgli Study Group (2001) Role of Mycoplasma pneumoniae and Chlamydia pneumoniae in children with communityacquired lower respiratory tract infections. Clin Infect Dis 32:1281-1289.

43. Esposito S, Blasi F, Allegra L, Principi N, the Mowgli Study Group (2001) The use of antimicrobials for community-acquired lower respiratory tract infections in hospitalized children. Eur J Clin Microbiol Infect Dis 20:647-650.

44.Principi N, Esposito S (2001) Emerging role of Mycoplasma pneumoniae and Chlamydia pneumoniae in paediatric respiratory tract infections. Lancet Infect Dis $1: 334-344$ 
Table 1. Demographic characteristics of the study population.

\begin{tabular}{|c|c|c|c|c|c|c|}
\hline & \multicolumn{3}{|c|}{ NICUs } & \multicolumn{3}{|c|}{ Pediatric wards } \\
\hline & $\begin{array}{c}\text { UK } \\
(n=62)\end{array}$ & $\begin{array}{l}\text { Italy } \\
(\mathrm{n}=38)\end{array}$ & $\begin{array}{r}\text { Greece } \\
(n=10)\end{array}$ & $\begin{array}{c}\text { UK } \\
(n=265)\end{array}$ & $\begin{array}{c}\text { Italy } \\
(n=94)\end{array}$ & $\begin{array}{l}\text { Greece } \\
(n=147)\end{array}$ \\
\hline Males (\%) & $33(53.2)$ & $25(65.8)$ & $6(60.0)$ & $144(54.3)$ & $56(59.6)$ & $89(60.5)$ \\
\hline \multicolumn{7}{|l|}{ Age } \\
\hline $0-27$ days, No. (\%) & $48(77.4)$ & $30(78.9)$ & $5(50.0)$ & $24(9.0)^{\mathrm{a}}$ & $2(2.1)$ & $4(2.7)$ \\
\hline 28 days-23 months, No. (\%) & $14(22.6)$ & $8(21.1)$ & $5(50.0)$ & $100(37.7)$ & $38(40.4)$ & $51(34.8)$ \\
\hline 2 years -11 years, No. (\%) & $0(0.0)$ & $0(0.0)$ & $0(0.0)$ & $102(38.5)^{b}$ & $47(50.0)$ & $80(54.4)$ \\
\hline 12 years -17 years, No. (\%) & $0(0.0)$ & $0(0.0)$ & $0(0.0)$ & $39(14.7)$ & $7(7.4)$ & $12(8.1)$ \\
\hline $\begin{array}{l}\text { Patients with underlying chronic } \\
\text { disease, No. (\%) }\end{array}$ & $50(80.6)$ & $32(84.2)$ & $8(80.0)$ & $150(56.6)^{\mathrm{c}}$ & $49(52.1)^{d}$ & $51(34.7)$ \\
\hline $\begin{array}{l}\text { Total number of antibiotic } \\
\text { prescriptions (mean per patient) }\end{array}$ & $172(2.77)$ & $91(2.39)$ & $27(2.70)$ & $545(2.05)$ & $160(1.70)$ & 249 (1.69) \\
\hline $\begin{array}{l}\text { Total number of antibiotics used } \\
\text { (mean per patient) }\end{array}$ & $13(0.20)$ & $10(0.26)$ & $15(1.5)$ & $32(0.12)$ & $29(0.30)$ & $29(0.19)$ \\
\hline $\begin{array}{l}\text { Total number of indications } \\
\text { (mean per patient) }\end{array}$ & $77(1.24)$ & $45(1.18)$ & $12(1.2)$ & $300(1.13)$ & $105(1.11)$ & $153(1.04)$ \\
\hline
\end{tabular}

NICUs: neonatal intensive care units; UK: United Kingdom. ${ }^{a} \mathrm{p}<0.05$ vs Italy and Greece; ${ }^{b} p<0.05$ vs Greece; ${ }^{c} p<0.0001$ vs Greece; no other significant between-country difference. 
Table 2. Antibiotics used at an unregistered dose in more than $5 \%$ of the prescriptions in at least one of the centers in patients admitted to NICUs.

UK Italy Greece

\begin{tabular}{|c|c|c|c|}
\hline & (No. of prescriptions $=172$ ) & (No. of prescriptions $=91$ ) & (No. of prescriptions $=27$ ) \\
\hline Antibiotics used at an unregistered dose, No. (\%) & $65(37.8)^{\mathrm{a}}$ & $47(51.7)$ & $12(44.4)$ \\
\hline \multicolumn{4}{|l|}{ Main molecules } \\
\hline Amikacin, No. (\%) & $27(15.7)$ & $12(13.2)$ & $3(11.1)$ \\
\hline Amoxicillin-clavulanate, No. (\%) & $0(0.0)^{a}$ & $6(6.6)$ & $0(0.0)$ \\
\hline Gentamicin, No. (\%) & $11(6.4)^{\mathrm{a}}$ & $17(18.7)$ & $1(3.7)$ \\
\hline Metronidazole, No. (\%) & $6(3.5)$ & $6(6.6)$ & $1(3.7)$ \\
\hline Trimethoprim, No. (\%) & $9(5.2)$ & $0(0.0)$ & $0(0.0)$ \\
\hline Vancomycin, No. (\%) & $4(2.3)$ & $4(4.4)$ & $3(11.1)$ \\
\hline Others, No. (\%) & $8(4.6)$ & $3(2.2)$ & $4(14.8)$ \\
\hline Higher than advised doses, No. (\%) & $5(2.9)^{b}$ & $8(8.8)$ & $6(22.2)$ \\
\hline Lower than advised doses, No. (\%) & $32(18.7)$ & $22(24.2)$ & $4(14.8)$ \\
\hline Incorrect frequency, No. (\%) & $28(16.3)$ & $17(18.7)$ & $2(7.4)$ \\
\hline \multicolumn{4}{|l|}{ Main indications } \\
\hline Medical prophylaxis, No. (\%) & $1(0.6)^{b, c}$ & $13(14.3)$ & $3(11.1)$ \\
\hline Sepsis, No. (\%) & $45(26.2)$ & $18(19.8)$ & $6(22.2)$ \\
\hline Surgical prophylaxis, No. (\%) & $9(5.2)$ & $4(4.4)$ & $0(0.0)$ \\
\hline Surgical treatment, No. (\%) & $9(5.2)$ & $9(9.9)$ & $0(0.0)$ \\
\hline Urinary tract infection, No. (\%) & $0(0.0)$ & $0(0.0)$ & $2(7.4)$ \\
\hline Others, No. (\%) & $1(0.6)$ & $3(3.3)$ & $1(3.7)$ \\
\hline Median gestational age at birth, weeks (range) & $31.2(23-41)$ & $32.6(24-41)$ & $32.9(24-39)$ \\
\hline Median age at prescription (range), days & $29(1-205)$ & $24(1-176)$ & $37(4-104)$ \\
\hline Patients with underlying chronic disease, No & $59(34.3)$ & $39(42.8)$ & $9(33.4)$ \\
\hline
\end{tabular}

NICU: neonatal intensive care unit; UK: United Kingdom. ${ }^{a} p<0.05$ vs Italy; ${ }^{b} p<0.05$ vs Greece; ${ }^{\circ} p<0.0001$ vs Italy; no other significant betweencountry difference. 
Table 3. Antibiotics used for an off-label indication in more than $5 \%$ of the prescriptions in at least one of the centers in patients admitted to NICUs.

\begin{tabular}{|c|c|c|c|}
\hline & $\begin{array}{c}\text { UK } \\
\text { (No. of prescriptions }=172 \text { ) }\end{array}$ & $\begin{array}{c}\text { Italy } \\
\text { (No. of prescriptions=91) }\end{array}$ & $\begin{array}{c}\text { Greece } \\
\text { (No. of prescriptions }=27 \text { ) }\end{array}$ \\
\hline Antibiotics used for an off-label indication, No. (\%) & $40(23.3)^{\mathrm{a}}$ & $35(38.5)$ & $7(25.9)$ \\
\hline \multicolumn{4}{|l|}{ Main molecules } \\
\hline Amoxicillin-clavulanate, No. (\%) & $1(0.6)^{\mathrm{a}}$ & $7(7.7)$ & $0(0.0)$ \\
\hline Ampicillin, No. (\%) & $0(0.0)^{a}$ & $13(14.3)$ & $1(3.7)$ \\
\hline Cefaclor, No. (\%) & $0(0.0)^{\mathrm{b}}$ & $0(0.0)^{b}$ & $2(7.4)$ \\
\hline Flucloxacillin, No. (\%) & $27(15.7)^{a, b}$ & $0(0.0)$ & $0(0.0)$ \\
\hline Gentamicin, No. (\%) & $0(0.0)^{\mathrm{a}}$ & $12(13.2)$ & $1(3.7)$ \\
\hline Others, No. (\%) & $12(7.0)^{\mathrm{a}}$ & $3(3.3)^{b}$ & $3(11.1)$ \\
\hline \multicolumn{4}{|l|}{ Main indications } \\
\hline Medical prophylaxis, No. (\%) & $0(0.0)^{\mathrm{c}}$ & $28(30.8)$ & $5(18.5)$ \\
\hline Sepsis, No. (\%) & $29(16.9)^{\mathrm{a}}$ & $4(4.4)$ & $1(3.7)$ \\
\hline Others, No. (\%) & $11(6.4)$ & $3(3.3)$ & $1(3.7)$ \\
\hline Mean gestational age at birth, weeks (range) & $28.4(23-41)$ & $33.5(24-41)$ & $33.2(25-38)$ \\
\hline Median age at prescription, days (range) & $30(1-192)$ & $22(1-176)$ & $35(4-104)$ \\
\hline Patients with underlying chronic disease, No. (\%) & $40(23.3)^{a}$ & $34(37.3)$ & $6(22.2)$ \\
\hline
\end{tabular}

NICU: neonatal intensive care unit; UK: United Kingdom. ${ }^{a} \mathrm{p}<0.05$ vs Italy; ${ }^{b} \mathrm{p}<0.05$ vs Greece; ${ }^{\mathrm{c}} \mathrm{p}<0.0001$ vs Italy and Greece; no other significant between-country difference. 
Table 4. Off-label antibiotics used at an unregistered dose in more than $5 \%$ of the prescriptions in at least one of the centers in patients admitted to pediatric wards.

\begin{tabular}{|c|c|c|c|}
\hline & UK & Italy & Greece \\
\hline & (No. of prescriptions $=545$ ) & (No. of prescriptions $=160$ ) & (No. of prescriptions $=249$ ) \\
\hline Antibiotics used at an unregistered dose, No. (\%) & $163(29.9)$ & $44(27.5)$ & $63(25.3)$ \\
\hline \multicolumn{4}{|l|}{ Main molecules } \\
\hline Amoxicillin-clavulanate, No. (\%) & $17(3.1)^{\mathrm{a}}$ & $13(8.1)$ & $5(2.0)^{a}$ \\
\hline Cefuroxime, No. (\%) & $5(0.9)^{b}$ & $0(0.0)^{\mathrm{b}}$ & $5(6.0)$ \\
\hline Gentamicin, No. (\%) & $64(11.7)^{a, c}$ & $2(1.2)$ & $2(0.8)$ \\
\hline Others, No. (\%) & $77(14.1)$ & $29(18.1)$ & $51(20.5)$ \\
\hline Higher than advised dose, No. (\%) & $62(11.4)$ & $26(16.3)$ & $38(15.3)$ \\
\hline Lower than advised dose, No. (\%) & $83(15.2)^{b}$ & $16(10.0)$ & $19(7.6)$ \\
\hline Incorrect frequency, No. (\%) & $18(3.3)$ & $2(1.3)$ & $6(2.4)$ \\
\hline \multicolumn{4}{|l|}{ Main indications } \\
\hline Lower respiratory tract infection, No. (\%) & $19(3.5)$ & $9(5.6)$ & $14(5.6)$ \\
\hline Sepsis, No. (\%) & $30(5.5)$ & $8(5.0)$ & $3(1.2)$ \\
\hline Surgical prophylaxis, No. (\%) & $50(9.2)$ & $9(5.6)$ & $13(5.2)$ \\
\hline Others, No. (\%) & $64(11.7)$ & $18(11.3)$ & $33(13.3)$ \\
\hline \multicolumn{4}{|l|}{ Age } \\
\hline 0-27 days, No. (\%) & $20(3.7)$ & $1(0.6)$ & $2(0.8)$ \\
\hline 28 days-23 months, No. (\%) & $47(8.6)^{\mathrm{a}}$ & $25(15.6)$ & $17(6.8)^{\mathrm{a}}$ \\
\hline 2-11 years, no. (\%) & $69(12.7)$ & $16(10.0)$ & $42(16.9)$ \\
\hline $12-17$ years, no. (\%) & $27(4.9)$ & $2(1.3)$ & $2(0.8)$ \\
\hline Median age (range), years & $5.34(0.01-17.30)^{a}$ & $3.80(0.04-14.49)$ & $4.43(0.03-13.27)^{a}$ \\
\hline Patients with underlying chronic disease, no. (\%) & $122(22.4)^{\mathrm{c}}$ & $30(18.8)^{b}$ & $26(10.4)$ \\
\hline
\end{tabular}

UK: United Kingdom. ${ }^{a} \mathrm{p}<0.05$ vs Italy; ${ }^{b} \mathrm{p}<0.05$ vs Greece; ${ }^{\mathrm{p}} \mathrm{p}<0.0001$ vs Greece; no other significant between-country difference. 
Table 5. Antibiotics used for an off-label indication in in more than $5 \%$ of the prescriptions in at least one of the centers in patients admitted to pediatric wards.

\begin{tabular}{|c|c|c|c|}
\hline & UK & Italy & Greece \\
\hline & (No. of prescriptions=545) & $\begin{array}{c}\text { (No. of } \\
\text { prescriptions }=160)\end{array}$ & $\begin{array}{c}(\text { No. of } \\
\text { prescriptions }=249)\end{array}$ \\
\hline $\begin{array}{l}\text { Antibiotics used for an off-label indication, No. (\%) } \\
\text { Main molecules }\end{array}$ & $155(28.4)^{a}$ & $48(30.0)^{\mathrm{a}}$ & $49(19.7)$ \\
\hline Amoxicillin-clavulanate, No. (\%) & $45(8.3)^{a}$ & $11(6.9)^{\mathrm{a}}$ & $4(1.6)$ \\
\hline Ampicillin-sulbactam, No. (\%) & $0(0.0)^{b}$ & $16(10.0)$ & $0(0.0)^{b}$ \\
\hline Gentamicin, No. (\%) & $27(5.0)^{a, c}$ & $0(0.0)$ & $0(0.0)$ \\
\hline Others, No. (\%) & $83(15.2)$ & $21(13.1)$ & $45(18.1)$ \\
\hline \multicolumn{4}{|l|}{ Main indications } \\
\hline Surgical prophylaxis, No. (\%) & $52(7.9)$ & $21(13.1)$ & $31(12.4)$ \\
\hline Surgical treatment, No. (\%) & $37(4.8)^{a}$ & $8(5.0)^{a}$ & $3(1.2)$ \\
\hline Others, No. (\%) & $66(12.1)^{a}$ & $19(11.9)$ & $15(6.0)$ \\
\hline \multicolumn{4}{|l|}{ Age } \\
\hline 0-27 days, No. (\%) & $11(2.0)$ & $1(0.6)$ & $0(0.0)$ \\
\hline 28 days-23 months, No. (\%) & $44(8.1)$ & $17(10.6)$ & $17(6.8)$ \\
\hline 2-11 years, No. (\%) & $71(13.0)$ & $23(14.4)$ & $23(9.3)$ \\
\hline $12-17$ years, No. (\%) & $29(5.3)$ & $7(4.4)$ & $9(3.6)$ \\
\hline Median age, years (range) & $5.61(0.01-16.88)$ & $5.74(0.04-16.29)$ & $5.85(0.13-15.09)$ \\
\hline Patients with underlying chronic disease, No. (\%) & $101(18.6)$ & $28(17.5)$ & $38(15.3)$ \\
\hline
\end{tabular}

UK: United Kingdom. ${ }^{a} \mathrm{p}<0.05$ vs Greece; ${ }^{b} \mathrm{p}<0.0001$ vs Italy; ${ }^{c} \mathrm{p}<0.05$ vs Italy; no other significant between-country difference. 


\section{OFF-LABEL ANTIBIOTIC USE IN CHILDREN IN THREE EUROPEAN COUNTRIES}

Alessandro Porta ${ }^{a}$, Susanna Esposito ${ }^{a}$, Esse Menson ${ }^{b}$, Nikos Spyridis $^{c}$, Maria Tsolia $^{c}$,

Mike Sharland $^{\mathrm{d}}$, Nicola Principi ${ }^{\mathrm{a}}$

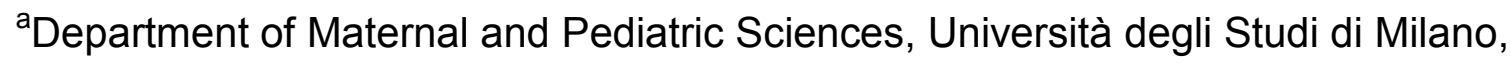

Fondazione IRCCS Ospedale Maggiore Policlinico, Mangiagalli e Regina Elena, Milan,

Italy; 'Evelina Children's Hospital, London, United Kingdom; 'P. and A. Kyriakou Children's

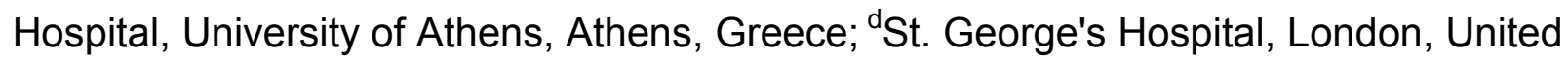

Kingdom.

Shortened title: Off-label antibiotics in children.

Key words: Antibiotics; antibiotic use; antimicrobials; antimicrobial prescribing; off-label drugs; children.

Abstract: 250 words.

Text: 3,161 words.

Correspondence and requests for reprints should be addressed to:

Nicola Principi,

Department of Maternal and Pediatric Sciences,

Università degli Studi di Milano,

Fondazione IRCCS “Ospedale Maggiore Policlinico, Mangiagalli e Regina Elena”,

Via Commenda 9,

20122 Milano,

Italy

Phone: +39-02-55032498; Fax: +39-02-50320206

E-mail: Nicola.principi@unimi.it 


\section{ABSTRACT}

Objective. Antibiotics are the drugs most frequently prescribed for children, and most of them lack patent protection. The aim of the present study was to evaluate off-label antibiotic use in three European countries.

Methods. The data concerning all patients admitted to the neonatal intensive care units (NICUs) and pediatric wards of the centers were collected by the same investigator over a two-week survey period between February and May 2009. Data included age, date of birth, weight, relevant medical history and diagnosis, together with details of all of the antibiotics prescribed (compound, route of administration, dose and indication for use). Results. The study involved 616 children (110 admitted to NICUs: 62 in the UK, 38 in Italy, and 10 in Greece; and 506 admitted to general pediatric wards: 265 in the UK, 94 in Italy and 147 in Greece) and a total of 1244 antibiotic prescriptions were issued (290 in NICUs and 954 in pediatric wards). The results show that off-label antibiotic use is very common in European pediatrics, with only slight but sometimes significant differences between countries. However, this use relates almost exclusively to doses and indications, and rarely to age. The only antibiotics used off-label for age in pediatric clinical practice were meropenem for neonates and quinolones or linezolid for older children, which represent priorities for future studies.

Conclusion. European-wide educational programmes are urgently needed to meet the objectives of improving paediatricians' working knowledge of the recommendations surrounding licensed antibiotics-use in children, and of reducing uncontrolled patterns of prescribing. 


\section{INTRODUCTION}

A number of hospital- and office-based studies have shown that many of the drugs prescribed to children are used outside their registered doses, age groups, indications and routes of administration [1-12]. This off-label use is related to the practical and ethical difficulties in carrying out clinical trials involving very young subjects. The extensive research required by current standards of drug evaluation in order to register a specific product for paediatric use is often not supported by the profit-driven drug industry because children represent only a small part of the drug market [13]. Furthermore, the limited pediatric drug research that is carried out is often based on small-scale studies that lack the statistical power necessary to draw any firm conclusions concerning the real efficacy of the drugs or their long-term toxic effects [14]. Ethical conflicts are heightened where the toxicity of medicines may be different in children and adults, compounded by issues around informed consent and assent [15].

Off-label drug use can cause significant damage in the developing fetus or child, one of the best examples being the grey baby syndrome due to chlorampenicol $[16,17]$; but it also gives rise to many minor but not marginal adverse events requiring hospitalisation or additional therapies [18-22]. A number of health authorities have recognised the need to conduct specific studies in children in order to reduce the problem of off-label use. The American Food and Drug Administration (FDA) has prepared the Best Pharmaceutical for Children Act and the Pediatric Research Equity Act, both of which are intended to incentivise drug research in children [23,24]: the first allows companies to qualify for an additional six months' exclusive marketing of a specific molecule provided that they carry out specific paediatric trials [23], and the second, which became law in 2003, states that the FDA can require pediatric studies of a drug for which a new drug application is submitted if it finds that the product is likely to be used in a substantial number of pediatric 
patients or would provide a significant benefit over existing treatments [24]. The European Medicines Agency (EMEA) has laid down specific rules for marketing authorisations of new medicinal products and for pediatric-use marketing authorisations of off-patent products [25]. It has also agreed a strategy for establishing the European network of pediatric research and providing information concerning pediatric clinical trials. Moreover, in order to encourage studies of drugs that lack patent protection because they have been marketed for many years, it has decided to prepare a list of drugs for which studies in children are urgently needed and can be financed by the European Union [26].

The drugs most frequently prescribed for children are antibiotics $[27,28]$, most of which lack patent protection. The aim of the present study was to evaluate off-label antibiotic use in three European countries.

\section{METHODS}

Antibiotic prescriptions were evaluated for all inpatients in the neonatal intensive care units (NICUs) and the pediatric medical and surgical wards of two hospitals in UK (St George's Hospital and Evelina Children's Hospital in London), one in Italy (Department of Maternal and Pediatric Sciences of the University of Milan), and one in Greece (Aglaia Kyriakou Children's Hospital, University of Athens). All data on the four sites were collected by the same investigator (AP) during a two-week survey of each hospital between February and May 2009. Data included age, date of birth, weight, relevant medical history and diagnosis, together with details of all of the antibiotics prescribed (compound, route of administration, dose and indication for use). The protocol was approved by the Institutional Review Board of all centres, and written informed consent was obtained from a parent or legal guardian, with children aged more than eight years being asked to give their assent. 
Off-label antibiotic use was determined on the basis of the information concerning product registration given in the British National Formulary 2009, the Italian Informatore Farmaceutico, and the Greek National Formulary 2006, as well as package insert information and what could be derived from the medical information departments of the pharmaceutical companies concerned. Off-label use was defined as the administration of an antibiotic in situations not covered by the product licence or the summary of product characteristics, or at a different dose or frequency, or to different age groups, or by means of an alternative route. The age groups considered were those defined by EMEA: neonates (0-27 days), infants (28 days to 23 months), children (2-11 years) and adolescents (12-17 years). The prescriptions were then divided into three groups depending on whether the off-label use was related to the patient's age, the drug dose, or the indication. A difference of $10 \%$ between the physician's prescription and the reference dose was allowed before considering the administration off-label.

Results were compared using SAS software, version 9.1 (SAS Institute, Cary, North Carolina). In Tables, only antibiotics prescribed at unregistered dose or for an off-label indication in more than $5 \%$ of the prescriptions in at least one of the centers are shown. Categorical variables are reported as numbers and percentages, and analysed by means of contingency tables and the chi-squared or Fisher's test. Continuous variables are given as mean values \pm standard deviation (SD), and analysed using a t test or Wilcoxon's test (for non-normally distributed data). P-values of 0.05 or less were considered to be statistically significant.

\section{RESULTS}

\section{Study population}


The study involved a total of 616 children (110 admitted to NICUs: 62 in the UK, 38 in Italy, and 10 in Greece; and 506 admitted to pediatric wards: 265 in the UK, 94 in Italy and 147 in Greece); a total of 1244 antibiotic prescriptions were issued for these patients (290 in NICUs and 954 in pediatric wards). Table 1 shows the demographic characteristics of the study patients. For NICU patients, there were no significant between-country differences in gender or age, or in the presence of underlying chronic conditions, number of antibiotic prescriptions, number of antibiotics used, or clinical indications for the antibiotic prescriptions. On pediatric wards, significantly more children in the neonatal age group were admitted in the UK than in Italy or Greece, and significantly fewer children aged 2-11 years were admitted in the UK than in Greece, while both UK and Italy hospitalised significantly more pediatric patients with underlying chronic diseases than Greece. However, there were no significant between country differences in gender, number of antibiotic prescriptions, number of antibiotics used, or clinical indications for the antibiotic prescriptions on paediatric wards.

\section{Antibiotic prescribing in neonatal units}

There were 12 episodes out of 290 prescriptions in which antibiotics were used outside the registered age range $(4.1 \%)$. Although there were small number of neonates in the Greek NICU during the study period, there were significantly fewer "outside age range" prescriptions in the UK $(4 / 172,4.3 \%)$ and Italy $(2 / 91,2.2 \%)$ than in Greece $(6 / 27,22.2 \%$; $p<0.05$ vs UK and Italy). The most frequent of such prescriptions in all centres was for meropenem (10/12 episodes, $83.3 \%$ ), which was prescribed because of proven or suspected sepsis in all cases. The Greek NICU also used imipenem (one case for lower respiratory tract infection) and ciprofloxacin (one case for urinary tract infection) outside age range. Moreover, the median gestational and chronological ages of the neonates in 
whom antibiotics were used outside the registered age range were significantly lower in Italy (median gestational age at birth 26 weeks and median age at prescription 24 days) than in the UK (median gestational age 31.7 weeks, $p<0.05$ vs Italy; median age 39.5 days, $p<0.05$ vs Italy) or Greece (median gestational age 33.7 weeks, $p<0.05$ vs Italy; median age 64 days, $p<0.05$ vs Italy). In the UK and Italian NICUs, the off-label use of antibiotics was related to patients with an underlying chronic disease in all cases, whereas in Greece this was true of only half of the cases.

Table 2 shows the antibiotics used at an unregistered dose in more than $5 \%$ of the prescriptions in at least one of the centers in patients admitted to NICUs. The number of such prescriptions was high in all of three countries, but significantly higher in Italy than in the UK. In all of the NICUs, the antibiotics most frequently prescribed at doses other than the recommended dose were aminoglycosides (particularly amikacin and gentamicin). Offlabel doses of gentamicin and also amoxicillin-clavulanate were prescribed significantly more often in the Italian NICU than in the UK units. In most cases, the differences regarded the administration of a lower than advised total daily dose or different fractioning. Higher than recommended doses were significantly more common in the Greek than in the UK NICUs. The most common clinical indication related to the use of off-label doses was proven or suspected sepsis in all three countries, although significantly more off-label doses for medical prophylaxis were prescribed in Italy and Greece than in the UK.

Table 3 shows the antibiotics used for an off-label indication in more than $5 \%$ of the prescriptions in at least one of the centers in the patients admitted to the NICUs. The prevalence of this use was similar in the UK and Greece, but higher in Italy. There were between-country differences in both the molecules and the individual indications. The antibiotics most frequently prescribed for an off-label indication were flucloxacillin in the UK, and ampicillin and gentamicin in Italy and Greece. The most common indications were 
suspected or proven sepsis in the UK, and medical prophylaxis in Italy and Greece. More Italian neonates with underlying chronic disease had off-label indications for the antibiotics received than UK or Greek neonates in NICUs.

\section{Antibiotic prescribing on paediatric wards}

Very few children in all centres received an antibiotic that was not licensed for pediatric use: there were 16 out of $954(1.7 \%)$ prescriptions in which antibiotics were used outside the registered age range. The antibiotics most frequently used outside the registered age range were quinolones $(11 / 16,68.8 \%)$ and linezolid $(5 / 16,31.2 \%)$, administered to children with a severe infection and an underlying chronic disease (mainly cystic fibrosis or leukemia). The median age of the patients receiving "outside age range" antibiotics was significantly higher in wards in the UK (median age at prescription 8.19 years) than in Italy (median age at prescription 4.25 years; $p<0.05$ vs UK) or Greece (median age at prescription 0.41 years).

Table 4 shows the antibiotics used at an unregistered dose in more than $5 \%$ of the prescriptions in at least one of the centers in patients admitted to pediatric wards. The proportion of prescriptions was quite similar in all of the centres, and the number of antibiotics involved was equally high across countries. In contrast, there were significant between-country differences in antibiotic choice, the most commonly prescribed being amoxicillin-clavulanate in Italy, cefuroxime in Greece, and gentamicin in the UK. The offlabel doses were mainly higher than advised in Italy and Greece, and lower than recommended in the UK. The main indications for off-label dosage were sepsis, lower respiratory tract infection and surgical prophylaxis in all three countries, with no difference in prevalence. Doses other than those recommended were used for children aged 28 days-23 months significantly more often in Italy than in the UK or Greece, with the median 
age of children receiving off-label doses being significantly lower in Italy than in the other two countries. Off-label doses were prescribed for children with underlying chronic disease significantly more often in the UK and Italy than in Greece.

Table 5 shows the antibiotics used for off-label indications in more than $5 \%$ of the prescriptions in at least one of the centers. The frequency of this use was significantly higher in the UK and Italy than in Greece. Amoxicillin-clavulanate was prescribed significantly more often in Italy than in Greece, and ampicillin-sulbactam significantly more often in Italy than in UK and Greece. The prevalence of use for off-label surgical treatment was significantly higher in the UK and Italy than in Greece. There were no significant between-country differences in the age distribution of the patients or the presence of an underlying chronic disease.

\section{DISCUSSION}

Over the last few years, several studies carried out in different settings have clearly demonstrated that the off-label use of drugs is frequent in pediatrics, especially in neonates [1-12]. However, most of them have considered all drugs prescribed to children and provided little details of prescription practice. To the best of our knowledge, this is the first study evaluating off-label antibiotic use in pediatrics that takes into account all of the variables involved in a drug prescription: the age of the patient, the total daily drug dose and its fractioning, and the indication for treatment.

Our findings suggest that pediatric off-label antibiotic use is very common in Europe with only marginal but sometimes significant between-country differences. However, this offlabel use almost exclusively relates to doses and indications rather than age as the only antibiotics not registered for specific age groups that neonatologists and pediatricians 
sometimes deem imperative in very serious clinical situations were meropenem for neonates and quinolones or linezolid for older children.

Sepsis in an NICU is a life-threatening disease that requires prompt and effective antibiotic treatment [29]. Published recommendations suggest that the empirical therapy for newborns should be based on a combination of ampicillin and an aminoglycoside, although the latter can cause severe adverse events and has to be administered cautiously in the first months of life [29]. However, most of the pathogens that cause neonatal bacterial sepsis have become highly resistant to the first-choice combination, especially in the case of a late-onset and probable nosocomial origin [30]. This means that alternative antibiotic therapies are needed, particularly for neonates who remain in NICUs for several days, and justifies the use of meropenem in some cases. Meropenem has a broad antibacterial spectrum, a very good safety profile, and good pharmacokinetic and pharmacodynamic characteristics [31]. However, although it has been widely successfully used to treat severe infections, including bacterial sepsis and meningitis in children and infants aged $\geq 3$ months [32], it has not yet been registered for neonates and infants aged $<3$ months. Our data show that comprehensive clinical research into its use for severe infections in this age group is a clinical priority for neonatologists.

Quinolones and linezolid are not licensed for use during the first 18 years of life but studies of quinolones have clearly demonstrated that ciprofloxacin and levofloxacin (the molecules used in the centres involved in this study) can be administered to pediatric patients with good results and without any significant adverse events [33,34]. Nevertheless, the use of quinolones should be limited to diseases caused by pathogens resistant to all of the other licensed drugs because they may rapidly select antimicrobial resistance in the case their widespread and uncontrolled administration. The situation of linezolid is similar as it is a relatively new drug for which pediatric experience is limited to complicated infections in 
patients with underlying chronic disease [35-37]. We found that quinolones and linezolid were mainly used in children with cystic fibrosis or oncohematological diseases in which complicated infections due to bacterial resistance to commonly used antibiotics is very frequent.

The high prevalence of antibiotic prescriptions for off-label indications or at unregistered doses in our NICUs and pediatric wards is in line with previously published data concerning the pediatric use of antibiotics [1-12]. It may be that pediatricians have a poor understanding of the properties and characteristics of antibiotics nor how they should be prescribed to treat bacterial diseases at different pediatric ages, but our findings raise some interesting afterthoughts.

First of all, certain antibiotics, especially aminoglycosides, were prescribed at below than recommended doses, mainly in the UK and Italian NICUs, which may reflect neonatologists' fear of known adverse effects [2] and a preferance to reduce the risk by limiting dosage rather than respecting published recommendations. The higher than recommended dosage of aminoglycosides observed for the NICU in Greece is difficult to explain, but it highlights the need for a comprehensive review of the dosing of potentially toxic antibiotics in such setting.

Secondly, the main off-label indications for which antibiotics were used in NICUs were proven or suspected sepsis in the UK, and medical prophylaxis in Italy and Greece. The rational approach to antibiotics in neonates involves using narrow-spectrum drugs whenever possible, treating infection and not colonisation, and limiting the duration of therapy [30], which makes it difficult to explain their use for off-label indications. It is possible that many of the antibiotics approved for use in neonates have been licensed for so long that the emergence of bacterial resistance is being observed or suspected, underpinning the tendency to move to off-license alternatives. 
Thirdly, for the pediatric inpatient populations, the number of prescriptions made at unregistered doses could be due to clinicians translating the findings of well-conducted post-marketing studies into their clinical practice. Aminoglycosides serve as a good example of this: having been licensed with the recommendation to divide the total daily dose into two or three administrations depending on the patients' age and renal function, subsequent clinical trials have shown equivalent or superior clinical outcome from once daily dosing of the total daily dose, with a reduced lower risk of toxicity $[38,39]$. Similarly, amoxicillin, licensed in children at a recommended dose of $40-50 \mathrm{mg} / \mathrm{kg} / \mathrm{day}$, proved to be effective against Streptococcus pneumoniae strains with relative resistance to penicillin when used at higher dose $(80-90 \mathrm{mg} / \mathrm{kg} / \mathrm{day})$ without concomitant increase in the incidence of adverse events $[40,41]$.

Evidence of the clinical effectiveness of other antimicrobials when used for off-label indications may also be influencing practice: for example, the use of macrolides for bronchitis or acute infectious wheezing was not considered appropriate until that the role of atypical bacteria was demonstrated in these diseases [42-44]. It may be, therefore that some of the off-label prescribing described in this study constituted active rational decision-making by clinicians based on the emerging evidence. However, how much offlabel prescribing is merely 'personal practice' error or experimentation without an appropriate clinical trial setting cannot be evaluated from this study.

In conclusion, although only four centres have been evaluated in our study and this limits the speculation on the possible causes of differences between countries as well as it does not really represent the entire European Union, our data confirm that the off-label use of antibiotics in newborns, infants and children is widespread and that the bulk of this cannot be justified on the grounds of optimizing clinical care. As suggested by the FDA and EMEA [23-26], studies of the antibiotics that are not licensed for specific pediatric age groups are 
urgently needed in order to evaluate how they should be administered in order to optimize clinical results while minimising the risk of adverse events. In the case of already licensed antibiotics, the studies performed after their licensing should be carefully reviewed and the recommendations modified when new knowledge acquired. Finally, national and European-wide educational programmes should meet the dual objectives of improving paediatricians' working knowledge of the recommendations surrounding licensed antibiotics-use in children, and of reducing uncontrolled patterns of prescribing that may increase the risk of antimicrobial resistance.

\section{ACKNOWLEDGEMENTS}

We would like to thank all of our colleagues who permitted data collection: Fabio Mosca, Lorenza Pugni, Maria Cristina Pietrogrande, Rosa Maria Dellepiane, Edoardo Calderini, Maurizio Torricelli at the Department of Maternal and Pediatric Sciences, Università degli Studi di Milano, Fondazione IRCCS Ospedale Maggiore Policlinico, Mangiagalli e Regina Elena, Milan, Italy; Dimitris Kafetzis, George Kourakis, George Petousis, Alexandros Passalidis at P. and A. Kyriakou Children's Hospital, University of Athens, Athens, Greece. The authors have no conflict of interest to declare. This study was supported in part by a grant from the Pediatric Unit 1, Fondazione IRCCS Ospedale Maggiore Policlinico, Mangiagalli e Regina Elena, Milan, Italy. 


\section{REFERENCES}

1. Conroy S, Mclntre J, Choonora I (1999) Unlicensed and off label drug use in neonates. Arch Dis Child Fetal Neonatal Ed 80:F142-F144.

2. Conroy S, Choonara I, Impicciatore I et al. (2000) Survey of unlicensed and off label drug use in paediatric wards in European countries. European network for Drug Investigation in Children. BMJ 320:79-82.

3. Turner S, Longworth A, Nunn AJ, Choonara I (1998) Unlicensed and off label drug use in paediatric wards: prospective study. BMJ 316:343-345.

4. 't Jong GW, Vulto AG, de Hoog M, Schimmel KJ, Tibboel D, van den Anker JN (2001) A survey of the use of off-label and unlicensed drugs in Dutch children's hospital. Pediatrics 108:1089-1093.

5. Schirm E, Tobi H, De Jong-Van den Berg LTW (2002) Unlicensed and off label drug use by children in the community: cross sectional study. Br Med J 324:13121313.

6. Bucheler R, Schwab M, Morike K ey al. (2002) Off-label prescribing to children in primary care in Germany: retrospective cohort study. Br Med J 324:1311-1312.

7. Pandolfini C, Campi R, Clavenna A, Cazzato T, Bonati M (2005) Italian paediatricians and off-label prescriptions: loyal to regulatory or guideline standards? Acta Paediatr 94:753-757.

8. Sammons H, Conroy S (2008) How do we ensure safe prescribing for children? Arch Dis Child 93:98-99.

9. Conroy S, Carroll WD (2009) Prescribing in pediatrics. Arch Dis Child Educ Pract Ed 94:55-59. 
10. Tafuri G, Trotta F, Leufkens HGM, Martini N, Sagliocca L, Traversa G (2009) Offlabel use of medicines in children: can available evidence avoid useless pediatric trials? Eur J Clin Pharmacol 65:209-216.

11. de Jong J, van den Berg PB, Visser ST, de Vries TW, de Jong-van den Berg LTW (2009) Antibiotic usage, dosage and course length in children between 0 and 4 years. Acta Paediatr 98:1142-1148.

12.Lenk C, Koch P, Zappel H, Wiesemann C (2009) Off-label, off-limits? Parental awareness and attitudes towards off-label use in paediatrics. Eur J Pediatr 168:1473-1478.

13. Conroy S, Mclntyre J, Choonara I, Stephenson T (2000) Drug trials in children: problems and the way forward. Br J Clin Pharmacol 49:93-97.

14.Pandolfini C, Bonati M, Sammons H (2009) Registration of trials in children. Update of current international initiatives. Arch Dis Child 94:717-719.

15. Altavilla A, Giaquinto C, Ceci A (2008) European survey on ethical and legal frame work of clinical trials in paediatrics: results and perspectives. J Int Bioethique 19:1748.

16. Holt D, Harvey D, Hurley R (1993) Chlorampenicol toxicity. Adverse Drug React Toxicol Rev 12:83-95.

17. Mclntyre J, Choonara I (2004) Drug toxicity in the neonate. Biol Neonate 86:218221.

18. Horen B, Montastruc JL, Lapeyre-Mestre M (2002) Adverse drug reactions and offlabel drug use in paediatric outpatients. Br J Clin Pharmacol 54:665-670.

19. Clarkson A, Choonara I (2002) Surveillance for fatal suspected adverse drug reactions in the UK. Arch Dis Child 87:462-466. 
20. Choonara I, Conroy S (2002) Unlicensed and off-label drug use in children: implications for safety. Drug Saf 25:1-5.

21. Turner S, Nunn AJ, Fielding K, Choonara I (1999) Adverse drug reactions to unlicensed and off-label drugs on paediatric wards: a prospective study. Acta Paediatr 88:965-968.

22. Johann-Liang R, Wyeth J, Chen M, Cope JU (2009) Pediatric drug surveillance and the Food and Drug Administration's adverse event reporting system: an overview of reports, 2003-2007. Pharmacoepidemiol Drug Saf 18:24-27.

23. Best Pharmaceuticals for Children Act. Pub. L. 107-109, 107 ${ }^{\text {th }}$ Cong, 2002.

24.Pediatric Research Equity Act. Pub. L. No. 108155 (S.650), 2003.

25. Neubert A, Wong IC, Bonifazi A et al. (2008) Defining off-label and unlicensed use of medicines for children: results of a Delphi survey. Pharmacol Res 58:316-322.

26. Ceci A, Felisi M, Baiardi P et al. (2006) Medicines for children licensed by the European Medicines Agency (EMEA): the balance after 10 years. Eur J Clin Pharmacol 62:947-952.

27. Marchetti F, Bua J, Ventura A, Notarangelo LD, Di Maio S, Migliore G, Bonati M (2007) The awareness among paediatricians of off-label prescribing in children: a survey of Italian hospitals. Eur J Clin Pharmacol 63:81-85.

28. Clavenna A, Sequi M, Bortolotti A, Merlino L, Fortino I, Bonati M (2009) Determinants of the drug utilization profile in the paediatric population in Italy's Lombardy Region. Br J Clin Pharmacol 67:565-571.

29.Burke C (2009) Perinatal sepsis. J Perinat Neonatal Nurs 23:42-51.

30.Fernando AM, Heath PT, Menson EN (2008) Antimicrobial policies in the neonatal units of the United Kingdom and Republic of Ireland. J Antimicrob Chemother $61: 743-745$. 
31. Arrieta A (1997) Use of meropenem in the treatment of serious infections in children: review of the current literature. Clin Infect Dis 24 Suppl. 2:S207-S212.

32. Principi N, Marchisio P (1998) Meropenem compared with ceftazidime in the empiric treatment of acute severe infections in hospitalized children. J Chemother 10:108-113.

33. Mandell LA, Peterson LR, Wise R et al. (2002) The battle against emerging antibiotic resistance: should fluoroquinolones be used to treat children? Clin Infect Dis 35:721-727.

34. Schaad UB (2005) Fluoroquinolone antibiotics in infants and children. Infect Dis Clin North Am 19:617-628.

35. Velissarious IM (2006) Use of linezolid in children: an overiew of recent advances. Expert Rev Anti Infect Ther 4:947-952.

36. Kosaka T, Kokufu T, Shime N, Sugioka N, Kato R, Hamaoka K, Fujita N (2009) Pharmacokinetics and tolerance of linezolid for meticillin-resistant Staphylococcus aureus mediastinitis in paediatric patients. Int J Antimicrob Agents 33:368-370.

37.Santos RP, Prestidge CB, Brown ME et al. (2009) Pharmacokinetics and pharmacodynamics of linezolid in children with cystic fibrosis. Pediatr Pulmonol 44:148-154.

38. Rao SC, Ahmed M, Hagan R (2006) One dose per day compared to multiple doses per day of gentamicin for treatment of suspected or proven sepsis in neonates. Cochrane Database Syst Rev 1:CD005091.

39. Hagen I, Øymar K (2009) Pharmacological differences between once daily and twice daily gentamicin dosage in newborns with suspected sepsis. Pharm World Sci $31: 18-23$ 
40.Dowell SF, Butler JC, Giebink GS et al. (1999) Acute otitis media: management and surveillance in an era of pneumococcal resistance - a report from the Drugresistant Streptococcus pneumoniae Therapeutic Working group. Pediatr Infect Dis J 18:1-9.

41.Piglansky L, Leibovitz E, Raiz S, Greenberg D, Press J, Leiberman A, Dagan R (2003) Bacteriologic and clinical efficacy of high dose amoxicillin for therapy of acute otitis media in children. Pediatr Infect Dis J 22:405-413.

42. Principi N, Esposito S, Blasi F, Allegra L, the Mowgli Study Group (2001) Role of Mycoplasma pneumoniae and Chlamydia pneumoniae in children with communityacquired lower respiratory tract infections. Clin Infect Dis 32:1281-1289.

43. Esposito S, Blasi F, Allegra L, Principi N, the Mowgli Study Group (2001) The use of antimicrobials for community-acquired lower respiratory tract infections in hospitalized children. Eur J Clin Microbiol Infect Dis 20:647-650.

44.Principi N, Esposito S (2001) Emerging role of Mycoplasma pneumoniae and Chlamydia pneumoniae in paediatric respiratory tract infections. Lancet Infect Dis $1: 334-344$ 
Table 1. Demographic characteristics of the study population.

\begin{tabular}{|c|c|c|c|c|c|c|}
\hline & \multicolumn{3}{|c|}{ NICUs } & \multicolumn{3}{|c|}{ Pediatric wards } \\
\hline & $\begin{array}{c}\text { UK } \\
(n=62)\end{array}$ & $\begin{array}{l}\text { Italy } \\
(\mathrm{n}=38)\end{array}$ & $\begin{array}{r}\text { Greece } \\
(n=10)\end{array}$ & $\begin{array}{c}\text { UK } \\
(n=265)\end{array}$ & $\begin{array}{c}\text { Italy } \\
(\mathrm{n}=94)\end{array}$ & $\begin{array}{l}\text { Greece } \\
(n=147)\end{array}$ \\
\hline Males (\%) & $33(53.2)$ & $25(65.8)$ & $6(60.0)$ & $144(54.3)$ & $56(59.6)$ & $89(60.5)$ \\
\hline \multicolumn{7}{|l|}{ Age } \\
\hline 0-27 days, No. (\%) & $48(77.4)$ & $30(78.9)$ & $5(50.0)$ & $24(9.0)^{a}$ & $2(2.1)$ & $4(2.7)$ \\
\hline 28 days-23 months, No. (\%) & $14(22.6)$ & $8(21.1)$ & $5(50.0)$ & $100(37.7)$ & $38(40.4)$ & $51(34.8)$ \\
\hline 2 years- 11 years, No. $(\%)$ & $0(0.0)$ & $0(0.0)$ & $0(0.0)$ & $102(38.5)^{b}$ & $47(50.0)$ & $80(54.4)$ \\
\hline 12 years -17 years, No. (\%) & $0(0.0)$ & $0(0.0)$ & $0(0.0)$ & $39(14.7)$ & $7(7.4)^{\prime}$ & $12(8.1)$ \\
\hline $\begin{array}{l}\text { Patients with underlying chronic } \\
\text { disease, No. }(\%)\end{array}$ & $50(80.6)$ & $32(84.2)$ & $8(80.0)$ & $150(56.6)^{c}$ & $49(52.1)^{d}$ & $51(34.7)$ \\
\hline $\begin{array}{l}\text { Total number of antibiotic } \\
\text { prescriptions (mean per patient) }\end{array}$ & $172(2.77)$ & $91(2.39)$ & $27(2.70)$ & $545(2.05)$ & $160(1.70)$ & 249 (1.69) \\
\hline $\begin{array}{l}\text { Total number of antibiotics used } \\
\text { (mean per patient) }\end{array}$ & $13(0.20)$ & $10(0.26)$ & $15(1.5)$ & $32(0.12)$ & $29(0.30)$ & $29(0.19)$ \\
\hline $\begin{array}{l}\text { Total number of indications } \\
\text { (mean per patient) }\end{array}$ & $77(1.24)$ & $45(1.18)$ & $12(1.2)$ & $300(1.13)$ & $105(1.11)$ & $153(1.04)$ \\
\hline
\end{tabular}

(mean per patient)

NICUs: neonatal intensive care units; UK: United Kingdom. ${ }^{a} p<0.05$ vs Italy and Greece; ${ }^{b} p<0.05$ vs Greece; ${ }^{c} p<0.0001$ vs Greece; no other significant between-country difference. 
Table 2. Antibiotics used at an unregistered dose in more than $5 \%$ of the prescriptions in at least one of the centers in patients admitted to NICUs.

\begin{tabular}{|c|c|c|c|}
\hline & $\begin{array}{c}\text { UK } \\
\text { (No. of prescriptions }=172 \text { ) }\end{array}$ & $\begin{array}{c}\text { Italy } \\
\text { (No. of prescriptions }=91 \text { ) }\end{array}$ & $\begin{array}{c}\text { Greece } \\
\text { (No. of prescriptions }=27 \text { ) }\end{array}$ \\
\hline Antibiotics used at an unregistered dose, No. (\%) & $65(37.8)^{a}$ & $47(51.7)$ & $12(44.4)$ \\
\hline \multicolumn{4}{|l|}{ Main molecules } \\
\hline Amikacin, No. (\%) & $27(15.7)$ & $12(13.2)$ & $3(11.1)$ \\
\hline Amoxicillin-clavulanate, No. (\%) & $0(0.0)^{a}$ & $6(6.6)$ & $0(0.0)$ \\
\hline Gentamicin, No. (\%) & $11(6.4)^{a}$ & $17(18.7)$ & $1(3.7)$ \\
\hline Metronidazole, No. (\%) & $6(3.5)$ & $6(6.6)$ & $1(3.7)$ \\
\hline Trimethoprim, No. (\%) & $9(5.2)$ & $0(0.0)$ & $0(0.0)$ \\
\hline Vancomycin, No. (\%) & $4(2.3)$ & $4(4.4)$ & $3(11.1)$ \\
\hline Others, No. (\%) & $8(4.6)$ & $3(2.2)$ & $4(14.8)$ \\
\hline Higher than advised doses, No. (\%) & $5(2.9)^{b}$ & $8(8.8)$ & $6(22.2)$ \\
\hline Lower than advised doses, No. (\%) & $32(18.7)$ & $22(24.2)$ & $4(14.8)$ \\
\hline Incorrect frequency, No. (\%) & $28(16.3)$ & $17(18.7)$ & $2(7.4)$ \\
\hline \multicolumn{4}{|l|}{ Main indications } \\
\hline Medical prophylaxis, No. (\%) & $1(0.6)^{b, c}$ & $13(14.3)$ & $3(11.1)$ \\
\hline Sepsis, No. (\%) & $45(26.2)$ & $18(19.8)$ & $6(22.2)$ \\
\hline Surgical prophylaxis, No. (\%) & $9(5.2)$ & $4(4.4)$ & $0(0.0)$ \\
\hline Surgical treatment, No. (\%) & $9(5.2)$ & $9(9.9)$ & $0(0.0)$ \\
\hline Urinary tract infection, No. (\%) & $0(0.0)$ & $0(0.0)$ & $2(7.4)$ \\
\hline Others, No. (\%) & $1(0.6)$ & $3(3.3)$ & $1(3.7)$ \\
\hline Median gestational age at birth, weeks (range) & $31.2(23-41)$ & $32.6(24-41)$ & $32.9(24-39)$ \\
\hline Median age at prescription (range), days & $29(1-205)$ & $24(1-176)$ & $37(4-104)$ \\
\hline Patients with underlying chronic disease, No. (\%) & $59(34.3)$ & $39(42.8)$ & $9(33.4)$ \\
\hline
\end{tabular}

NICU: neonatal intensive care unit; UK: United Kingdom. ${ }^{a} p<0.05$ vs Italy; ${ }^{b} p<0.05$ vs Greece; ${ }^{c} p<0.0001$ vs Italy; no other significant betweencountry difference. 
Table 3. Antibiotics used for an off-label indication in more than $5 \%$ of the prescriptions in at least one of the centers in patients admitted to NICUs.

\begin{tabular}{|c|c|c|c|}
\hline & $\begin{array}{c}\text { UK } \\
\text { (No. of prescriptions }=172 \text { ) }\end{array}$ & $\begin{array}{c}\text { Italy } \\
\text { (No. of prescriptions=91) }\end{array}$ & $\begin{array}{c}\text { Greece } \\
\text { (No. of prescriptions }=27 \text { ) }\end{array}$ \\
\hline Antibiotics used for an off-label indication, No. (\%) & $40(23.3)^{\mathrm{a}}$ & $35(38.5)$ & $7(25.9)$ \\
\hline \multicolumn{4}{|l|}{ Main molecules } \\
\hline Amoxicillin-clavulanate, №. (\%) & $1(0.6)^{\mathrm{a}}$ & $7(7.7)$ & $0(0.0)$ \\
\hline Ampicillin, No. (\%) & $0(0.0)^{\mathrm{a}}$ & $13(14.3)$ & $1(3.7)$ \\
\hline Cefaclor, No. (\%) & $0(0.0)^{\mathrm{b}}$ & $0(0.0)^{b}$ & $2(7.4)$ \\
\hline Flucloxacillin, No. (\%) & $27(15.7)^{\mathrm{a}, \mathrm{b}}$ & $0(0.0)$ & $0(0.0)$ \\
\hline Gentamicin, No. (\%) & $0(0.0)^{a}$ & $12(13.2)$ & $1(3.7)$ \\
\hline Others, No. (\%) & $12(7.0)^{\mathrm{a}}$ & $3(3.3)^{b^{\prime}}$ & $3(11.1)$ \\
\hline \multicolumn{4}{|l|}{ Main indications } \\
\hline Medical prophylaxis, No. (\%) & $0(0.0)^{\mathrm{c}}$ & $28(30.8)$ & $5(18.5)$ \\
\hline Sepsis, No. (\%) & $29(16.9)^{a}$ & $4(4.4)$ & $1(3.7)$ \\
\hline Others, No. (\%) & $11(6.4)$ & $3(3.3)$ & $1(3.7)$ \\
\hline Mean gestational age at birth, weeks (range) & $28.4(23-41)$ & $33.5(24-41)$ & $33.2(25-38)$ \\
\hline Median age at prescription, days (range) & $30(1-192)$ & $22(1-176)$ & $35(4-104)$ \\
\hline Patients with underlying chronic disease, No. (\%) & $40(23.3)^{a}$ & $34(37.3)$ & $6(22.2)$ \\
\hline
\end{tabular}

NICU: neonatal intensive care unit; UK: United Kingdom. ${ }^{a} p<0.05$ vs Italy; ${ }^{b} p<0.05$ vs Greece; ${ }^{c} p<0.0001$ vs Italy and Greece; no other significant between-country difference. 
Table 4. Off-label antibiotics used at an unregistered dose in more than $5 \%$ of the prescriptions in at least one of the centers in patients admitted to pediatric wards.

\begin{tabular}{|c|c|c|c|}
\hline & $\begin{array}{c}\text { UK } \\
\text { (No. of prescriptions }=545)\end{array}$ & $\begin{array}{c}\text { Italy } \\
\text { (No. of prescriptions }=160)\end{array}$ & $\begin{array}{c}\text { Greece } \\
\text { (No. of prescriptions }=249 \text { ) }\end{array}$ \\
\hline Antibiotics used at an unregistered dose, No. (\%) & 163 (29.9) & $44(27.5)$ & $63(25.3)$ \\
\hline \multicolumn{4}{|l|}{ Main molecules } \\
\hline Amoxicillin-clavulanate, No. (\%) & $17(3.1)^{\mathrm{a}}$ & $13(8.1)$ & $5(2.0)^{\mathrm{a}}$ \\
\hline Cefuroxime, No. (\%) & $5(0.9)^{b}$ & $0(0.0)^{b}$ & $5(6.0)$ \\
\hline Gentamicin, No. (\%) & $64(11.7)^{\mathrm{a}, \mathrm{c}}$ & $2(1.2)$ & $2(0.8)$ \\
\hline Others, No. (\%) & $77(14.1)$ & $29(18.1)$ & $51(20.5)$ \\
\hline Higher than advised dose, No. (\%) & $62(11.4)$ & $26(16.3)$ & $38(15.3)$ \\
\hline Lower than advised dose, No. (\%) & $83(15.2)^{b}$ & $16(10.0)$ & $19(7.6)$ \\
\hline Incorrect frequency, No. (\%) & $18(3.3)$ & $2(1.3)$ & $6(2.4)$ \\
\hline \multicolumn{4}{|l|}{ Main indications } \\
\hline Lower respiratory tract infection, No. (\%) & $19(3.5)$ & $9(5.6)$ & $14(5.6)$ \\
\hline Sepsis, No. (\%) & $30(5.5)$ & $8(5.0)$ & $3(1.2)$ \\
\hline Surgical prophylaxis, No. (\%) & $50(9.2)$ & $9(5.6)$ & $13(5.2)$ \\
\hline Others, No. (\%) & $64(11.7)$ & $18(11.3)$ & 33 (13.3) \\
\hline \multicolumn{4}{|l|}{ Age } \\
\hline $0-27$ days, No. (\%) & $20(3.7)$ & $1(0.6)$ & $2(0.8)$ \\
\hline 28 days-23 months, No. (\%) & $47(8.6)^{a}$ & $25(15.6)$ & $17(6.8)^{\mathrm{a}}$ \\
\hline $2-11$ years, no. (\%) & 69 (12.7) & $16(10.0)$ & $42(16.9)$ \\
\hline $12-17$ years, no. $(\%)$ & 27 (4.9) & $2(1.3)$ & $2(0.8)$ \\
\hline Median age (range), years & $5.34(0.01-17.30)^{\mathrm{a}}$ & $3.80(0.04-14.49)$ & $4.43(0.03-13.27)^{\mathrm{a}}$ \\
\hline Patients with underlying chronic disease, no. (\%) & $122(22.4)^{\mathrm{c}}$ & $30(18.8)^{b}$ & $26(10.4)$ \\
\hline
\end{tabular}

UK: United Kingdom. ${ }^{a} p<0.05$ vs Italy; ${ }^{b} p<0.05$ vs Greece; ${ }^{c} p<0.0001$ vs Greece; no other significant between-country difference. 
Table 5. Antibiotics used for an off-label indication in in more than $5 \%$ of the prescriptions in at least one of the centers in patients admitted to pediatric wards.

\begin{tabular}{|c|c|c|c|}
\hline & $\begin{array}{c}\text { UK } \\
\text { (No. of prescriptions }=545 \text { ) }\end{array}$ & $\begin{array}{c}\text { Italy } \\
\text { (No. of } \\
\text { prescriptions }=160)\end{array}$ & $\begin{array}{c}\text { Greece } \\
\text { (No. of } \\
\text { prescriptions }=249 \text { ) }\end{array}$ \\
\hline Antibiotics used for an off-label indication, No. (\%) & $155(28.4)^{a}$ & $48(30.0)^{\mathrm{a}}$ & $49(19.7)$ \\
\hline \multicolumn{4}{|l|}{ Main molecules } \\
\hline Amoxicillin-clavulanate, No. (\%) & $45(8.3)^{a}$ & $11(6.9)^{\mathrm{a}}$ & $4(1.6)$ \\
\hline Ampicillin-sulbactam, No. (\%) & $0(0.0)^{b}$ & $16(10.0)$ & $0(0.0)^{b}$ \\
\hline Gentamicin, No. (\%) & $27(5.0)^{a, c}$ & $0(0.0)$ & $0(0.0)$ \\
\hline Others, No. (\%) & $83(15.2)$ & $21(13.1)$ & $45(18.1)$ \\
\hline \multicolumn{4}{|l|}{ Main indications } \\
\hline Surgical prophylaxis, No. (\%) & $52(7.9)$ & $21(13.1)$ & $31(12.4)$ \\
\hline Surgical treatment, No. (\%) & $37(4.8)^{a}$ & $8(5.0)^{a}$ & $3(1.2)$ \\
\hline Others, No. (\%) & $66(12.1)^{\mathrm{a}}$ & $19(11.9)$ & $15(6.0)$ \\
\hline \multicolumn{4}{|l|}{ Age } \\
\hline $0-27$ days, No. (\%) & $11(2.0)$ & $1(0.6)$ & $0(0.0)$ \\
\hline 28 days-23 months, No. (\%) & $44(8.1)$ & $17(10.6)$ & $17(6.8)$ \\
\hline $2-11$ years, No. $(\%)$ & $71(13.0)$ & $23(14.4)$ & $23(9.3)$ \\
\hline $12-17$ years, No. $(\%)$ & $29(5.3)$ & $7(4.4)$ & $9(3.6)$ \\
\hline Median age, years (range) & $5.61(0.01-16.88)$ & $5.74(0.04-16.29)$ & $5.85(0.13-15.09)$ \\
\hline Patients with underlying chronic disease, No. (\%) & $101(18.6)$ & $28(17.5)$ & $38(15.3)$ \\
\hline
\end{tabular}

UK: United Kingdom. ${ }^{a} \mathrm{p}<0.05$ vs Greece; ${ }^{b} \mathrm{p}<0.0001$ vs Italy; ${ }^{\mathrm{c}} \mathrm{p}<0.05$ vs Italy; no other significant between-country difference. 